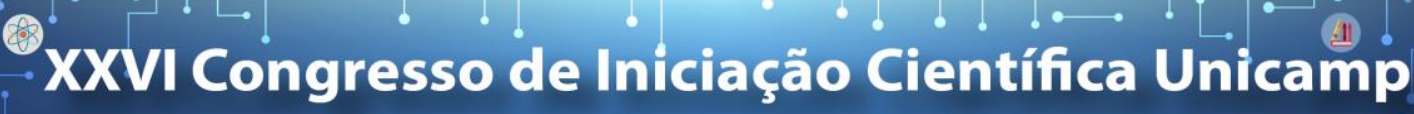

\section{SISTEMA DE INFORMAÇÃO BASEADO NO MODELO PARA EDIFICAÇÕES HISTÓRICAS}

\section{Gabriel Rodrigues da Rocha*, Raphael Di Gregorio Gomes, Rayssa J. Oliveira de Paula, Eloisa Dezen-Kempter.}

\begin{abstract}
Resumo
Este projeto de pesquisa teve como objetivo analisar o sistema de informação baseado no modelo aplicado a edificações históricas. Trata-se de uma pesquisa aplicada a um objeto de estudo, o Palacete Tatuhiby em Limeira inaugurado em 1901 e que atualmente se encontra abandonado. Foram realizadas varreduras digitais (escaneamento à laser e fotogrametria) para captura dos dados geoespaciais. Os dados foram processados e analisados em programas computacionais priorizando aspectos como precisão e facilidade de pós-processamento de informações. Com base nestes dados foi elaborado o modelo BIM desta edificação. O resultado mostrou a importância da captura e modelagem das informações das edficações históricas para sua preservação.
\end{abstract}

\section{Palavras-chave:}

Building Information Modeling, Varredura Digital, Patrimônio Histórico.

\section{Introdução}

A modelagem da informação da construção (BIM) tornouse uma tecnologia fundamental no processo de tomada de decisão e no fluxo de informações entre os colaboradores nas fases de projeto e construção, principalmente para novos edifícios. Para edificações existentes essa tecnologia ainda apresenta limitações principalmente na relação da modelagem as-is (QUATTRINI et.al., 2015).

Quanto à abordagem metodológica para a criação de modelos inteligentes para edificações existentes, Volk et al. (2014) e Tang et al. (2010) descrevem as três etapas fundamentais para o processo: (1) levantamento de dados (espaciais e documentais); (2) processamento de dados e criação do modelo denso de superfície (DSM); e (3) modelagem BIM (a partir do reconhecimento de componentes no DSM e sua etiquetagem semântica). Portanto, o DSM é a ponte entre o objeto real e sua representação BIM.

Esta pesquisa foi baseada em Volk et al. (2014) e Tang et al. (2010), para a criação do Modelo BIM de um edifício representativo da história da cidade de Limeira, SP, o Palacete Tatuhiby. O levantamento da condição como construído (as-is) do edifício empregou dois sensores na varredura digital: um escâner a laser terrestre (TLS) e um veículo aéreo não tripulado (VANT), cuja acurácia do levantamento foi comparada com a varredura a laser.

\section{Resultados e Discussão}

No intuito de verificar a acurácia do levantamento com o drone, as nuvens de pontos geradas pela varredura fotogramétrica foram comparadas com as nuvens de pontos geradas pelo escâner a laser terrestre (TLS) através do Software Cloud Compare. Apesar de a literatura científica considerar a nuvem de pontos da restituição fotogramétrica com erros superiores ao do laser os resultados obtidos até o momento indicam que a qualidade da nuvem da fotogrametria está bem próxima do levantamento à laser, medidos em termos de densidade de pontos por $\mathrm{m}^{3}$ e variação dimensional com relação ao objeto levantado.

O modelo BIM foi criado usando o DSM como base. A nuvem foi trabalhada no ReCAP (Autodesk) visando gerar o formato para a importação para outras plataformas Autodesk (.RCP), como o Autocad e o REVIT. O modelo BIM foi criado no REVIT da Autodesk.

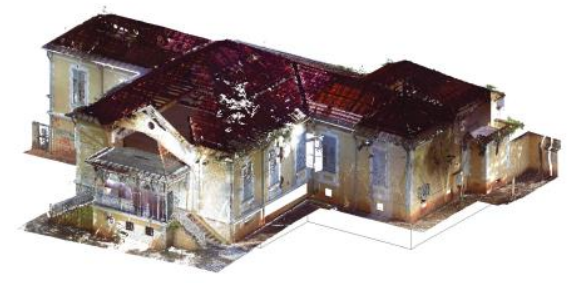

Figura 1. Nuvem de pontos do Palacete importada no REVIT.

\section{Conclusões}

Esta pesquisa demonstrou potencial no levantamento digital para documentação as-is de edificações históricas. O modelo BIM representa uma ferramenta fundamental para processos de manutenção e restauro pois permite gravar informações detalhadas sobre o edifício e seus componentes.

1 Volk, R., Stengel, J., \& Schultmann, F. Building Information Modeling (BIM) for existing buildings-Literature review and future needs. Automation in construction, 2014, 38, 109-127

2 Tang, P., Huber, D., Akinci, B., Lipman, R., \& Lytle, A. Automatic reconstruction of as-built building information models from laser-scanned point clouds: A review of related techniques. Automation in construction, 2010, 19(7), 829-843.

3 Quattrini, R., Malinverni, E. S., Clini, P., Nespeca, R., Orlietti, E. From TLS to HBIM. High quality semantically-aware $3 \mathrm{~d}$ modeling of complex architecture, International Archives of the Photogrammetry, Remote Sensing and Spatial Information Sciences, 2015 Avila, Spain, Volume XL, Part 5/W4, pp. 367-374. 